\title{
Feeding styles of caregivers of children 6-23 months of age in Derashe special district, Southern Ethiopia
}

Mekitie Wondafrash ${ }^{1,2^{*}+}$, Tseganeh Amsalu ${ }^{3+}$ and Mirkuzie Woldie ${ }^{4+}$

\begin{abstract}
Background: Apart from basic determinants, appropriate child care practices are important in prevention of growth faltering and undernutrition. Providing safe and appropriate quality complementary foods is crucial to child growth and development. However, some children in low-income communities grow normally mainly due to proper caregiver feeding behaviors. Hence, the objective of this study was to determine caregivers' feeding styles as well as to indentify predictors in Derashe special district, Southern Ethiopia.
\end{abstract}

Methods: A community based cross-sectional study design was employed in the seven randomly selected Kebeles (smallest administrative unit) of Derashe special district. A total of 826 caregivers provided data pertaining to sociodemographic variables. However, 764 caregivers had complete data for the outcome variable (caregiver feeding style). A multistage stratified sampling technique was used to identify study subjects. An adapted Caregiver's Feeding Styles Questionnaire (CFSQ) was used to gather information about caregivers' feeding styles. Multivariate multinomial logistic regression was employed to identify predictors of caregivers' feeding style.

Results: The majority (80.6\%) of caregivers were biological mothers. Nearly seventy-six percent of the caregivers practiced a responsive feeding style. Caregivers other than the biological mother favoured a laissez-faire feeding style, while caregivers residing in rural Kebeles were more responsive. Caregivers with a breastfeeding frequency of more than eight times predicted both laissez-faire (RRR $=1.88 ; 95 \% \mathrm{Cl}=1.03-3.41)$ and controlling (RRR $=1.7 ; 95 \%$ $\mathrm{Cl}=1.02-2.85)$ feeding styles as compared to responsive feeding.

Conclusion: Responsive feeding was the commonest style practiced by the caregivers. Many of the caregivers who were rural residents and birth parents have been responsive in child feeding. The instruments needed to be validated in the Ethiopian context and an additional prospective study based on direct observation of caregiverchild interactions is recommended.

\section{Background}

Malnutrition is the largest risk factor in the world for disability and premature mortality among young children, especially in developing countries [1,2]. Although the condition is entirely preventable, malnutrition is a significant underlying factor in more than half of the deaths of young children in these countries [1,3]. Malnutrition is a background factor for deaths from diarrhea, measles, acute respiratory infection, meningitis and malaria [4].

\footnotetext{
* Correspondence: mwondafrash@yahoo.com

+ Contributed equally

'Department of Population and Family Health, Jimma University, Jimma, Ethiopia

Full list of author information is available at the end of the article
}

In Ethiopia, $47 \%, 11 \%$ and $38 \%$ of children under five years of age are stunted, wasted and underweight, respectively [5]. An Ethiopian child is 30 times more likely to die by his or her fifth birthday than a child in Western Europe and the most common cause of child death is the interacting combination of malnutrition and infection [6]. Malnutrition is a complex phenomenon that stems from various underlying determinants, including a lack of optimal feeding practices for infants and young children. In UNICEF's conceptual framework for determinants of nutritional status, maternal and child care practices have been given due attention in addition to sufficient food supply at the household level, access to health services and a clean environment [7]. Some children in low-income

\section{() Biomed Central}


countries with high rates of malnutrition grow normally due to better education and household management, or coping skills of their mothers [8]. Moreover, proper feeding practices, which ensure intake, are as important as the provision of complementary foods that meet nutritional requirements.

The caregiver-child interaction (feeding style) critically influences dietary intake on top of the dietary aspect of child feeding [9]. However, comparing feeding styles between studies prior to 1995 was difficult due to a lack of consistency in terminology and unclear definitions of feeding styles [10]. Later on, feeding styles were conceptualized and defined by Birch and Fisher as controlling, laissezfaire, and responsive feeding styles [11], and have been used in different researches $[9,12,13]$.

The "controlling" feeding style occurs when a caregiver has complete control of when, what and how much the child eats, and includes restriction and force-feeding the child. In the "laissez-faire" feeding style the caregiver makes little effort to encourage eating; feeding is not encouraged even when the child may be marginally nourished [14]. Birch and Fisher defined the term "responsive" feeding as a condition in which "the caregiver is in close proximity to the young child during the meal and responds to the child's hunger cues in a reasonable time" [11]. Responsiveness is now viewed by different authors as a three-step process, namely observation of child cues by the caregiver, interpretation of the signs and taking action as quickly as possible in response to those cues $[8,13,15]$.

Appropriate child feeding practices and behaviors of parents have a positive effect on growth of infants and young children [16]. For instance, an analysis of data sets from several Latin American countries demonstrated that appropriate breastfeeding and complementary feeding practices were positively associated with child height-forage in most of the countries studied [17]. However, the majority of the literature on child feeding and parental practices are based on women in affluent societies and their emphases have been on child overweight or obesity [18-20]. Control over feeding appears to vary among cultures, socioeconomic status and child's gender [21]. Hence, results of the effect of different parental or caregiver feeding behaviors among various socio-cultural settings should be used cautiously.

Most studies carried out in Ethiopia have focused mainly on identifying factors associated with undernutrition instead of overweight or obesity [5,22]. To the best of our knowledge, no studies have been conducted to assess child feeding behavior of caregivers and the association between these behaviors and child growth and development, dietary intake, eating behavior or morbidity in Ethiopia. Current interventions mainly address the issue of what to feed young children instead of how to feed them [8]. The aim of this study was to identify the different types of child feeding behaviors (styles) of caregivers and the factors that influence these behaviors.

\section{Methods}

\section{Study area and setting}

A community based cross-sectional study was conducted in January 2009 in Derashe special district, Southern Ethiopia. Based on the 2007 census, the projected total population of the district in 2009 was 149,901 and the total household count was 29,980. Children 6-23 months of age constituted $6.7 \%$ of the total population. The livelihood of more than $92 \%$ of the district population is based on farming. The main crops grown in the area are maize, sorghum and teff (a species of Eragrostis native to Ethiopia).

\section{Sampling}

The source population of this study included all residents of Derashe district who were caregivers of children aged 6-23 months and resided in the district for more than 6 months. The sample size was calculated by using the single population proportion formula. Assumptions for the calculation were that $50 \%$ of caregivers practiced a "responsive" feeding style (P) with a 95\% confidence level and $5 \%$ tolerable error. The calculated sample size was 384. As a multistage sampling technique was employed to identify study subjects, a design effect of 2 was used to reach a sample size of 768 to which $10 \%$ was added for non-responses. Thus, the final sample size was 845 .

A multistage stratified sampling technique was used to identify study subjects after the Kebeles (smallest administrative units) were stratified into urban and rural Kebeles. Based on the proportion of population by urban-rural residence [23], seven rural and one urban Kebele were randomly selected in the district. A census was conducted in the selected Kebeles to identify households with children aged 6-23 months and to generate a sampling frame. A total of 3021 children in this age group who were started with complementary food were identified and listed. The calculated sample (845) was proportionally allocated to the selected Kebeles based on the total number of caregivers of 6-23 months children in each Kebele and study subjects were identified by simple random sampling technique.

\section{Method of data collection}

Data was collected by a face-to-face interview technique using the adapted Caregiver's Feeding Styles Questionnaire $[24,25]$. The questionnaire was first prepared in English and later translated into Amharic (the local language) and back translated into English to check for its conceptual equivalence. Prior to the actual data collection, the questionnaire was pre-tested using $5 \%$ of the sample from a similar population outside the study area. Twelve high 
school complete data collectors, with previous experience in nutritional surveys, were recruited and trained by the principal investigators on the study instrument and data collection procedures. Reliability of the measurements was assured by training two health officers from the district for close follow-up. The principal investigators constantly checked strict adherence to the standards agreed upon by all field workers.

\section{Measurement of caregivers' feeding styles}

Data collectors asked the caregivers to respond to behavioral and belief items pertaining to each feeding style. However, many caregivers displayed behaviors and beliefs of more than one feeding style which made strict categorization into the three styles (controlling, laissez- faire or responsive) according to Birch and Fisher [11] difficult. Hence, those caregivers practicing a particular style most of the time for behavioral items, or agreeing or highly agreeing with a belief item, were considered as practicing responsive, controlling or laissez-faire feeding styles depending on the response to each behavioral and belief item. The behavioral and belief items of the questionnaire were adapted to the local context from similar studies conducted using a validated instrument.

\section{Data analysis}

The data was analyzed using Stata version 11 (StataCorp, College Station, TX, USA). Nineteen caregivers were not found despite repeated visits. Sixty two questionnaires with inadequate information to measure caregiver feeding style were excluded making the total observation with complete information 764. Bivariate and multivariate multinomial logistic regression was employed to assess statistical associations between caregivers' feeding style and caregiver and child characteristics. Residence, age of caregiver and the study child, relation of the study child with the caregiver, educational status of the caregiver and the father of the study child, parity of the biological mother, birth interval between the study child and older sibling, frequency of breastfeeding and advice on child feeding by a health professional were entered as independent variables in the model. Responsive feeding style was used as a reference category in the model.

Variables which showed a significant association with caregivers' feeding style in the bivariate analysis, were entered into the multivariate multinomial logistic regression. Relative Risk Ratios (RRR), the relative risk ratios for the multinomial logistic model, were determined to assess whether the risk of the outcome falling in the comparison group (either controlling or laissez- faire feeding style) compared to the risk of the outcome falling in the reference group (responsive feeding style) increases or decreases with the independent variable. The $\mathrm{p}$-value $(\mathrm{P}>$ $|z|)$, is the probability that the $\mathrm{z}$ test statistic would be as extreme as, or more so, than what has been observed under the null hypothesis. If $\mathrm{P}>|\mathrm{z}|$ is less than 0.05 , the null hypothesis can be rejected and the RRR is considered significant at the $5 \%$ level.

\section{Ethical considerations}

Ethical approval was obtained from the Ethical Review Committee of Jimma University. Informed consent was secured from all caregivers of study children before commencing the interview.

\section{Results}

General characteristics of caregivers and study children Of the 845 sampled caregivers, 826 were successfully included in the study making the response rate $97.7 \%$. Biological mothers accounted for 666 (80.6\%) of caregivers, while 160 (19.4\%) were other caregivers such as grandmothers, sisters and other relatives. Most of the caregivers (87.6\%) were rural residents. Fifty percent of the respondents were 25-34 years of age. Seventy percent of the caregivers did not attend any formal education and 172 (71.7\%) of those who attended school attended only elementary school. Three hundred fifty-nine (54.5\%) of the biological mothers, who were at the same time caregivers, had given birth to only one child. Five hundred and sixty five $(79.9 \%)$ received advice from health professionals about child feeding (Table 1).

The majority of interviewed caregivers (61.6\%) had 12 23 month old children (Table 2). Biological mothers were the main caregivers of most of the 6-11 month old children (87\%), while grandmothers were caregivers of 20 (6.4\%) of these children. Mothers and grandmothers were the main caregivers of 396 (76.5\%) and 64 (12.5\%) of the 12-23 month old children, respectively (data not shown).

\section{Breastfeeding and complementary feeding practices of caregivers}

Six hundred sixty three $(80.2 \%)$ of the caregivers were breastfeeding at the time of the study. Among the caregivers who specified breastfeeding frequency, $64.9 \%$ were feeding their children less than eight times per day. Two hundred ninety three (38.7\%) of the interviewed caregivers had started giving complementary foods or drinks other than breast milk (mostly water, gruel and other semisolid cereal-based preparations) to their infants before they reached 6 months of age. For half of the caregivers, the reason for introducing foods/drinks too early was the belief that breast milk alone is not sufficient at that age. The mean $( \pm$ SD) complementary feeding frequency was $4.6 \pm 1.3,5.1 \pm 1.4$ and $6.2 \pm 1.6$ times per day for study children 6-8, 9-11 and 12-24 months of age, respectively. Thirty eight percent of the study children ate from a separate bowl (data not shown). 
Table 1 Characteristics of caregivers of study children in Derashe special district, Southern Ethiopia

\begin{tabular}{|c|c|c|}
\hline Variables & Frequency & Percent \\
\hline \multicolumn{3}{|c|}{ Residence of the caregiver $(n=826)$} \\
\hline Urban & 103 & 12.5 \\
\hline Rural & 723 & 87.5 \\
\hline \multicolumn{3}{|c|}{ Age of the caregiver (years) $(n=826)$} \\
\hline$<20$ & 87 & 10.5 \\
\hline $20-24$ & 145 & 17.6 \\
\hline $25-29$ & 260 & 31.5 \\
\hline 30-34 & 156 & 18.9 \\
\hline$>=35$ & 178 & 21.5 \\
\hline \multicolumn{3}{|c|}{ Relation of the study child with the caregiver $(n=826)$} \\
\hline Mother & 666 & 80.6 \\
\hline Others* & 160 & 19.4 \\
\hline \multicolumn{3}{|c|}{ Educational status of the caregiver $(n=826)$} \\
\hline No formal education & 582 & 70.5 \\
\hline Elementary & 175 & 21.2 \\
\hline Above elementary & 69 & 8.4 \\
\hline \multicolumn{3}{|c|}{ Educational status of the father of study child $(n=826)$} \\
\hline No formal education & 376 & 45.5 \\
\hline Elementary & 251 & 30.4 \\
\hline Above elementary & 199 & 24.1 \\
\hline \multicolumn{3}{|c|}{ Parity of the biological mother $(n=666)$} \\
\hline Primiparous & 118 & 17.7 \\
\hline Multiparous & 341 & 51.2 \\
\hline Grand multiparous & 207 & 31.1 \\
\hline \multicolumn{3}{|c|}{ Advice on young child feeding by a health professional $(n=716)$} \\
\hline Advised & 565 & 78.9 \\
\hline Not advised & 151 & 21.1 \\
\hline
\end{tabular}

*Grandmothers, sisters, other relatives

Table 2 Characteristics of the study children in Derashe special district, Southern Ethiopia

\begin{tabular}{lll}
\hline Variables & Frequency & Percent \\
\hline Age of the study child $(\mathbf{n}=\mathbf{8 2 6})$ & 188 & 22.8 \\
\hline 6-8 months & 129 & 15.6 \\
\hline $9-11$ months & 509 & 61.6 \\
\hline $12-23$ months & & 50.5 \\
\hline Sex $(\mathbf{n}=\mathbf{8 2 6})$ & 417.0 & 49.5 \\
\hline Male & 409.0 & \\
\hline Female & & 66.2 \\
\hline Birth interval between the study and older sibling $(\mathbf{n}=\mathbf{6 3 7})$ & 422 & 33.8 \\
\hline Short birth interval & 215 & \\
\hline Optimal birth interval & & 64.9 \\
\hline Frequency breast feeding in the last $\mathbf{2 4}$ hours $\mathbf{( n = 6 6 6 )}$ & 432 & 35.1 \\
\hline Less than recommended & 234 & \\
\hline Recommended & & \\
\hline
\end{tabular}




\section{Feeding styles of caregivers}

The majority (75.7\%) of caregivers fed their children mostly with a "responsive" feeding style, followed by "controlling" and "laissez-faire" in 98 (12.8\%) and 88 $(11.5 \%)$ of the caregivers, respectively. On the other hand, $660(80.0 \%)$ and $670(81.2 \%)$ of the caregivers replied that the study child refused to eat if he/she was not hungry and when he/she was ill, respectively. Seventy seven $(9.3 \%), 52(6.4 \%)$ and $7(0.9 \%)$ of the caregivers replied that the study child refused to eat if he/ she was forced to eat, if someone other than the caregiver was feeding him/her and if he/she was not encouraged to eat, respectively (data not shown).

In response to food refusal by the child, 512 (66.9\%) of the caregivers encouraged their children to eat either verbally or physically. According to the responses of 405 $(53.0 \%)$ of the caregivers, the children ate more when encouraged verbally, while $292(38.2 \%)$ of the respondents replied that the children ate more when food was provided on a separate plate (Table 3 ). Five hundred eighty $(70.3 \%)$ of the caregivers fed their sick child by verbal or physical encouragement. However, 182 (22.0\%) of the caregivers force-fed their children during illness while $71(8.7 \%)$ used other options to help their children eat under similar circumstances.

\section{Predictors of caregiver feeding styles} Laissez-faire relative to responsive feeding style

The laissez-faire style is characterized by the lack of extra effort by the caregiver in making the child eat even if the child is at risk of undernutrition. Caregivers from rural villages were less likely $(R R R=0.16 ; 95 \%$
$\mathrm{CI}=0.08-0.33)$ to practice a laissez-faire feeding style compared to a responsive feeding style given that the other variables in the model are kept constant. Caregivers other than biological mothers (RRR $=2.5$; $95 \%$ $\mathrm{CI}=1.43-4.38)$, who breastfed more than eight times during the previous day $(\mathrm{RRR}=1.88 ; 95 \% \mathrm{CI}=1.03$ 3.41) and biological mothers with an optimal birth interval between study child and older sibling $(R R R=2.46$; $95 \% \mathrm{CI}=1.38-4.40)$ were more likely to practice a laissez-faire feeding style compared to a responsive feeding style (Table 4).

\section{Controlling relative to responsive feeding style}

Caregivers with a controlling feeding style try to control the time, type and the amount of food the child eats. They may also practice force-feeding when the child refuses to eat. Caregivers who were not biological mothers, compared to biological mothers, were more likely $(R R R=1.86$; $95 \% \mathrm{CI}=1.1-3.15)$ to practice a controlling feeding style compared to responsive feeding. Caregivers who breastfed more than eight times during the previous day compared to those feeding less frequently were more likely $(R R R=$ $1.7 ; 95 \% \mathrm{CI}=1.02-2.85$ ) to practice a controlling feeding style. Moreover, it was also found that biological mothers with an optimal birth interval between study child and older sibling were less likely $(\mathrm{RRR}=0.55$; 95\% CI $=0.32$ $0.95)$ to practice a controlling feeding style compared to a responsive feeding style (Table 4).

\section{Discussion}

This study examined three types of caregivers' feeding styles (laissez-fair, controlling, responsive) from a sociodemographic, child feeding and caregivers' behavior

Table 3 Caregivers' feeding styles, responses to child's refusal to eat and conditions in which child eats more, Derashe special district, Southern Ethiopia

\begin{tabular}{lll}
\hline Variables & Frequency & Percent \\
\hline Caregivers' feeding style $(\mathbf{n}=\mathbf{7 6 4})$ & 88 & 11.5 \\
\hline Laissez-faire & 98 & 12.8 \\
\hline Controlling & 578 & 75.7 \\
\hline Responsive & 512 & 66.9 \\
\hline Active responses for food refusal* & 239 & 31.2 \\
\hline Encourage him/her to eat verbally or physically & 18.4 \\
\hline Offers the same food later & 141 & 11.1 \\
\hline Offers alternative foods (favorite foods) & 84 & 5.4 \\
\hline Forces the child to feed & 41 & 53.0 \\
\hline Do not try any solutions & & 38.2 \\
\hline Condition in which the child eats more* & 405 & 27.0 \\
\hline When encouraged to eat & 292 & 4.6 \\
\hline When food is presented in a separate plate & 221 & \\
\hline When the caregiver sits with the child while the child is eating & 47 & \\
\hline Forcing the child to eat & & \\
\hline
\end{tabular}

*There were multiple responses by a caregiver 
Table 4 Multinomial logistic regression of predictors of feeding style of caregivers, Derashe special district, Southern Ethiopia

\begin{tabular}{|c|c|c|c|c|}
\hline Caregivers' feeding style & $\mathrm{RRR} *$ & $P>|z|$ & $\begin{array}{l}{[95 \%} \\
\text { Inte }\end{array}$ & $\begin{array}{l}\text { Conf. } \\
\text { rval] }\end{array}$ \\
\hline \multicolumn{5}{|l|}{ Laissez-faire } \\
\hline Rural residence by the caregiver & 0.16 & 0.000 & 0.08 & 0.33 \\
\hline Caregiver other than a biological mother & 2.50 & 0.001 & 1.43 & 4.38 \\
\hline $\begin{array}{l}\text { Frequency of BF more than eight times in } \\
\text { the previous } 24 \text { hours }\end{array}$ & 1.88 & 0.038 & 1.03 & 3.41 \\
\hline $\begin{array}{l}\text { Optimal birth interval between the study } \\
\text { child and older sibling ( } 36-60 \text { months) }\end{array}$ & 2.46 & 0.002 & 1.38 & 4.40 \\
\hline \multicolumn{5}{|l|}{ Controlling } \\
\hline Caregiver other than a biological mother & 1.86 & 0.02 & 1.10 & 3.15 \\
\hline $\begin{array}{l}\text { Frequency of BF more than eight times in } \\
\text { the previous } 24 \text { hours }\end{array}$ & 1.70 & 0.043 & 1.02 & 2.85 \\
\hline $\begin{array}{l}\text { Optimal birth interval between the study } \\
\text { child and older sibling ( } 36-60 \text { months) }\end{array}$ & 0.54 & 0.038 & 0.30 & 0.97 \\
\hline
\end{tabular}

*RRR = Relative Risk Ratio; $\mathrm{n}=764$; The reference category is "Responsive feeding style"

perspective. The majority of the studies investigating these three child feeding styles were carried out in developed countries and used a variety of techniques and instruments. This made direct comparisons of the findings from this study with other findings difficult.

In this study, $51 \%$ of the children were exclusively breastfed at 6 months of age. This is much higher than the findings reported in the Ethiopian Demographic and Health Survey 2005 (EDHS 2005). The EDHS 2005 report showed that only one in three children of 4-5 months of age were exclusively breastfed and that the rate of exclusive breastfeeding for those less than 6 months was $49 \%$ [5]. This might be because EDHS 2005 was a nationally representative survey with a wide range of exclusive breastfeeding proportions in different regions of Ethiopia.

The WHO recommends children of 6-8, 9-11 and 12-23 months of age to be fed 2-3, 3-4 and 3-4 times per day, respectively, with the addition of 1-2 snacks [9]. In this study, $95 \%$ of the children within each of these respective age groups received complementary foods as frequent or more than the WHO recommendation. The mean $( \pm \mathrm{SD})$ complementary feeding frequency per day was $4.6 \pm 2.0$, $5.2 \pm 1.8$ and $5.2 \pm 2.0$ times for children in the respective age groups. This result was comparable to the findings from rural Malawi where the mean $( \pm \mathrm{SD})$ complementary feeding frequency was $3.1 \pm 1.2,4.1 \pm 1.1$ and $4.4 \pm 1.4$ times, respectively [26]. The majority of caregivers were classified as practicing a responsive child feeding style (75.7\%) which is consistent with the findings from a study in Vietnam [12].

In this study, $80.6 \%$ of caregivers were biological mothers. A study conducted in Nicaragua showed that mothers, as caregivers, were more likely than other caregivers to offer encouragement for eating [27]. Most of the caregivers in this study were rural dwellers but practiced a responsive feeding style most of the time. Two thirds of rural mothers in Bangladesh practiced active feeding ("behavior that encourages the child to eat or the mother to feed, either indirectly through words or directly through forcing food into the child's mouth") but only a third of them were responsive [28].

Caregivers' behavior in child feeding are part of the broader socio-cultural context of societies in different geographical locations [29]. Several studies suggested that appropriate child feeding practices have an impact on child nutritional status $[10,15-17,20,30]$. Responsive or active feeding was found to be more beneficial to the child in some low- or middle-income countries $[15,27,31,32]$ and non-responsive feeding was associated with child BMI and overweight or obesity in high-income countries [20] though, cross-study definitions of responsive feeding were inconsistent. Responsiveness was also observed in reaction to a child's decreased appetite during diarrheal episodes in Guatemala [33] and Peru [34]; and low interest in food in Nicaragua [27]. However, recent reviews concluded that the effect of responsive feeding on child weight or growth was mixed and failed to isolate the effect of responsive feeding, as most of these studies were done together with broader health or nutrition education and food supplementation programs [15] and used cross-sectional designs [20]. Moreover, the mechanism of linking feeding behavior and child weight or growth differs between low- and middle-income and high-income countries [15,20].

In developing countries, there is very little information on the practice of controlling or laissez-faire feeding and implications for child nutrition. In Ghana, it was found that using force during feeding was common among caregivers with negative deviance in child feeding and had a direct effect on child's nutrient intake [32]. In Nigeria, force-feeding and pressurizing was followed by food refusal by the child [35]. In Vietnam, non-responsive feeding, characterized by pressure or force-feeding, was associated with the child's rejection of the food [36]. A recent study in Malawi revealed that controlling feeding behavior was negatively associated with the acceptance of food by the child [37].

Unlike the present study, a laissez-faire feeding style was the most frequently observed behavior among caregivers in Peru and Guatemala [33,34]. Encouraging feeding in these circumstances was a response only to a decrease in child food intake because of illness and hence was not pro-active.

This study did not assess the outcome of a particular feeding style practiced by caregivers, though the available literature on feeding styles underlined the association of feeding style with child growth and development, acceptance of food or child eating behavior and overweight or 
obesity [14,30,38-41]. As a limitation of the cross-sectional study design, temporality could not be established. Hence, it is difficult to determine whether a positive child response to the provided food leads to responsive feeding by caregivers or vice versa [15]. Nevertheless, behavior at any point in time could reflect prior caregiver-child interactions. The results of this study are also dependent on the reporting of the caregiver. Most studies used additional observations through videotaping of caregivers feeding behaviors which can increase the validity of the finding from interview-based studies [38].

\section{Conclusions and Recommendations}

Responsive feeding was the commonest style practiced by the studied caregivers. In this study, rural residence and being a biological mother were found to be independent predictors of responsive feeding after controlling for potential confounders. As this study was the first of its kind in the country, more research is needed to check the validity and reliability of the Caregiver's Feeding Styles Questionnaire in Ethiopia and to evaluate the effect of caregivers' feeding style on child dietary intake and nutritional status in different socio-cultural settings within the country. Moreover, longitudinal research starting from early infancy is recommended to see the factors affecting caregiver's child feeding behavior and other care practices.

\section{Acknowledgements}

We would like to forward our gratitude to Jimma University, College of Public Health and Medical Sciences for the financial support. We also thank the supervisors, data collectors and respondents, and the Derashe special district health office

\section{Author details}

${ }^{1}$ Department of Population and Family Health, Jimma University, Jimma, Ethiopia. ${ }^{2}$ Department of Food Safety and Food Quality, Faculty of Bioscience Engineering, Ghent University, Ghent, Belgium. ${ }^{3}$ MercyCorps Ethiopia, Arba Minch, Ethiopia. ${ }^{4}$ Department of Health Services Management, Jimma University, Jimma, Ethiopia.

\section{Authors' contributions}

MW, TA and $\mathbf{M W}$ designed the study, analyzed the data, drafted the manuscript, and hence had equal contribution. All authors read and approved the final manuscript.

\section{Competing interests}

The authors declare that they have no competing interests.

Received: 26 July 2011 Accepted: 23 March 2012

Published: 23 March 2012

\section{References}

1. Muller $\mathrm{O}$, Krawinkel M: Malnutrition and health in developing countries. Can Med Assoc J 2005, 173:279-286

2. FAO/WHO: International Conference on Nutrition Goals. World Declaration and Plan of Action.FAO, Rome and WHO, Geneva. 1992

3. Pelletier DL: The relationship between child anthropometry and mortality in developing countries: implications for policy, programs and future research. J Nutr Oct 1994, 124(10 Suppl):2047S-2081S.
4. Pelletier DL, Frongillo EA Jr, Schroeder DG, Habicht JP: The effects of malnutrition on child mortality in developing countries. Bull World Health Organ 1995, 73:443-448.

5. Central Statistical Authority, ORC Macro: Ethiopia Demographic and Health Survey 2005. Addis Ababa, Ethiopia and Calverton, Maryland, USA: CSA and ORC. 2006

6. Joan J, Mesfin BH: Report on review of Incorporation of Essential Nutrition Actions into Public Health Programs in Ethiopia; Food and Nutrition Technical Assistance (FANTA) Project, Academy for Educational Development (AED) Ethiopia: Addis Ababa; 2008.

7. UNICEF: The care initiative assessment, analysis, and action to improve care for nutrition. New York: UNICEF Nutrition Section. 1997.

8. Pelto GH: Improving complementary feeding practices responsive parenting as a primary component of interventions to prevent malnutrition in infancy and early childhood. Pediatrics 2000, 106:1300-1301.

9. Ruel MT, Brown KH, Caulfield LE: Moving forward with complementary feeding: indicators and research priorities. International Food Policy Research Institute (IFPRI) discussion paper 146 (April 2003). Food Nutr Bull 2003, 24:289-290.

10. Dettwyler KA, Fishman C: Infant Feeding Practices and Growth. Annual Review of Anthropology 1992, 21:171-204.

11. Birch $L L$, Fisher JA: Appetite and eating behavior in children. PediatrClin N Am 1995, 42(4):931-953.

12. Ha PB, Bentley ME, Pachón H, Sripaipan T, Caulfield LE, Marsh DR, Schroeder DG: Caregiver styles of feeding and child acceptance of food in rural Viet Nam. In Food and Nutrition Bulletin. Volume 23. The United Nations University; 2002(4(supplement)).

13. Eshel N, Daelmans B, Mello MCd, Martines J: Responsive parenting: interventions and outcomes. Bull World Health Organ 2006, 84:991-998.

14. Dettwyler KA: Styles of Infant Feeding: Parental/Caretaker Control of Food Consumption in Young Children. American Anthropologist 1989, 91:696-703.

15. Bentley ME, Wasser HM, Creed-Kanashiro HM: Responsive Feeding and Child Undernutrition in Low- and Middle-Income Countries. J Nutr 2011, 141:502-507.

16. Saha KK, Frongillo EA, Alam DS, Arifeen SE, Persson LÃk, Rasmussen KM: Appropriate infant feeding practices result in better growth of infants and young children in rural Bangladesh. Am J ClinNutr 2008, 87:1852-1859.

17. Ruel MT, Menon P: Child Feeding Practices Are Associated with Child Nutritional Status in Latin America: Innovative Uses of the Demographic and Health Surveys. J Nutr 2002, 132:1180-1187.

18. Crouch $P, O^{\prime}$ Dea JA, Battisti R: Child feeding practices and perceptions of childhood overweight and childhood obesity risk among mothers of preschool children. Nutrition \& Dietetics 2007, 64:151-158.

19. May AL, Donohue M, Scanlon KS, Sherry B, Dalenius K, Faulkner P, Birch LL: Child-feeding strategies are associated with maternal concern about children becoming overweight, but not children's weight status. J Am Diet Assoc 2007, 107:1167-1175

20. Hurley KM, Cross MB, Hughes SO: A Systematic Review of Responsive Feeding and Child Obesity in High-Income Countries. The Journal of Nutrition 2011, 141:495-501.

21. Hupkens CLH, Knibbe RA, van Otterloo AH, Drop MJ: Class differences in the food rules mothers impose on their children: a cross-national study. Social Science \&amp; Medicine 1998, 47:1331-1339.

22. Girma W, Timotiows G: Determinants of Nutritional Status of Women and Children in Ethiopia: further analyis of Ethiopia Demographic and Health Survey 2000 Calverton, Maryland, USA: ORC Macro; 2002.

23. Federal Democratic Republic of Ethiopia Population Census Commission: Summary and statistical report of the 2007 population and housing census; population size by age and sex. Addis Ababa, Ethiopia. 2008.

24. Hughes SO, Power TG, Orlet Fisher J, Mueller S, Nicklas TA: Revisiting a neglected construct: parenting styles in a child-feeding context. Appetite 2005, 44:83-92.

25. Patrick H, Nicklas TA, Hughes SO, Morales M: The benefits of authoritative feeding style: caregiver feeding styles and children's food consumption patterns. Appetite 2005, 44:243-249.

26. Hotz C, Gibson RS: Complementary feeding practices and dietary intakes from complementary foods amongst weanlings in rural Malawi. Eur J ClinNutr 2001, 55:841-849. 
27. Engle $\mathrm{PL}$, Zeitlin M: Active feeding behavior compensates for low interest in food among young Nicaraguan children. J Nutr 1996, 126:1808-1816.

28. Moore AC, Akhter S, Aboud FE: Responsive complementary feeding in rural Bangladesh. SocSci Med 2006, 62:1917-1930.

29. Engle $\mathrm{PL}$, Bentley $\mathrm{M}$, Pelto $\mathrm{G}$ : The role of care in nutrition programmes: current research and a research agenda. ProcNutrSoc 2000, 59:25-35.

30. Galler JR, Ramsey FC, Harrison RH, Brooks R, Weiskopf-Bock S: Infant Feeding Practices in Barbados Predict Later Growth. J Nutr 1998, 128:1328-1335.

31. Aboud FE, Moore AC, Akhter S: Effectiveness of a community-based responsive feeding programme in rural Bangladesh: a cluster randomized field trial. Matern Child Nutr 2008, 4:275-286.

32. Nti CA, Lartey A: Effect of caregiver feeding behaviours on child nutritional status in rural Ghana. International Journal of Consumer Studies 2007, 31:303-309.

33. Bentley M, Caulfield L, Torun B, Schroeder D, Hurtado E: Maternal feeding behavior and child appetite during acute diarrhea and subsequent health in Guatemala. FASEB J 1992, 6:A436.

34. Bentley M, Stallings RY, Fukumoto M, Elder J: Maternal feeding behavior and child acceptance of food during diarrhea episodes, convalescence, and health in the Central NorthernSierra of Peru. Am J Public Health 1991, $83: 1-5$.

35. Brown KH, Dickin KL, Bentley ME, Oni GA, Obassajju VT, Esrey SA, Mebrahtu S, Alade I, Stallings RY: Consumption of weaning foods from fermented cereals: Kwara State, Nigeria. Inlmproving Young Child Feeding in Eastern and SouthernAfrican Household-level Food Technology. Proceedings of a Workshop, pp 181-197 [D Alnwick, S Moses and OG Schmidt, editors] Ottawa, Ont: IDR 1988.

36. Ha PB, Bentley ME, Pachón H, Sripaipan T, Caulfield LE, Marsh DR, Schroeder DG: Caregiver styles of feeding and child acceptance of food in rural Viet Nam. Food Nutr Bull 2002, 23:95-100.

37. Flax VL, Mäkinen S, Ashorn U, Cheung YB, Maleta K, Ashorn P, Bentley ME: Responsive feeding and child interest in food vary when rural Malawian children are fed lipid-based nutrient supplements or local complementary food. Maternal \& Child Nutrition .

38. Sacco LM, Bentley ME, Carby-Shields K, Borja JB, Goldman BD: Assessment of infant feeding styles among low-income African-American mothers: Comparing reported and observed behaviors. Appetite 2007, 49:131-140.

39. Hoerr S, Hughes S, Fisher J, Nicklas T, Liu Y, Shewchuk R: Associations among parental feeding styles and children's food intake in families with limited incomes. Int J BehavNutrPhys Act 2009, 6:55.

40. Birch LL, Fisher JO: Mothers' child-feeding practices influence daughters' eating and weight. Am J ClinNutr 2000, 71:1054-1061.

41. Aboud FE, Alemu T: Nutrition, maternal responsiveness and mental development of Ethiopian children. SocSci Med 1995, 41:725-732.

\section{Pre-publication history}

The pre-publication history for this paper can be accessed here: http://www.biomedcentral.com/1471-2458/12/235/prepub

doi:10.1186/1471-2458-12-235

Cite this article as: Wondafrash et al.: Feeding styles of caregivers of children 6-23 months of age in Derashe special district, Southern Ethiopia. BMC Public Health 2012 12:235.

\section{Submit your next manuscript to BioMed Central and take full advantage of:}

- Convenient online submission

- Thorough peer review

- No space constraints or color figure charges

- Immediate publication on acceptance

- Inclusion in PubMed, CAS, Scopus and Google Scholar

- Research which is freely available for redistribution

Submit your manuscript at www.biomedcentral.com/submit
Biomed Central 